\title{
Effects of the eukaryotic initiation factor 6 gene on expression levels of inflammatory mediators in M2 macrophages during scar repair
}

\author{
YONG-QIANG BAI ${ }^{*}$, JIAN-KE FENG* ${ }^{*}$, QING-FU ZHANG, HONG-ZHI WU, YA-RU DU and WEI WEI
}

Department of Burns and Plastic Surgery, The First Hospital of Hebei Medical University, Shijiazhuang, Hebei 050031, P.R. China

Received April 16, 2015; Accepted March 14, 2016

DOI: $10.3892 / \mathrm{mmr} .2016 .5294$

\begin{abstract}
The aim of the present study was to evaluate the effects of the eukaryotic initiation factor 6 (eIF6) gene on the secretion of M2 macrophage fibrosis-associated factors and the expression levels of key proteases during scar repair. Male eIF6 wild-type $\left(\mathrm{eIF6}^{+/+}\right)$and knockout $\left(\mathrm{eIF6}^{+-}\right)$C57BL/6 mice were intraperitoneally lavaged to obtain macrophages, which were induced to the M2 type using interleukin-4. Differences between the gene expression profiles of these macrophages were compared with gene microarrays, and the results were validated using reverse transcription-quantitative polymerase chain reaction analysis and ELISA. Compared with the eIF6 ${ }^{+}$ mice, the mRNA and protein expression levels of vascular endothelial growth factor (VEGF) and tissue inhibitor of metalloproteinase-2 (TIMP-2) in the M2 macrophages of the $\mathrm{eIF6}^{+/+}$mice were significantly downregulated $(\mathrm{P}<0.05)$, whereas the mRNA and protein expression levels of matrix metalloproteinase-2 (MMP-2) were significantly upregulated $(\mathrm{P}<0.05)$. Therefore, the results indicated that eIF6 alleviated cicatrization, possibly by inhibiting the generation of VEGF, in order to prevent overgrowth of blood vessels and granulation tissues, and to regulate the MMP-2/TIMP-2 ratio to balance the degradation and deposition of the extracellular matrix.

\section{Introduction}

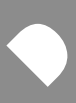

Cicatrization, or fibrosis, is a normal, inevitable physiological response, which occurs during natural post-burn healing, however, it is clinically challenging due to the severe effect on quality of life. Macrophages are important in wound healing
\end{abstract}

Correspondence to: Dr Wei Wei, Department of Burns and Plastic Surgery, The First Hospital of Hebei Medical University, 89 Donggang Road, Shijiazhuang, Hebei 050031, P.R. China

E-mail:weiweidbps@163.com

*Contributed equally

Key words: eukaryotic initiation factor 6, macrophage, fibrosis and fibrosis (1). Lucas et al (2) found that eliminating macrophages delayed wound healing by decreasing granulation tissue growth and inhibiting re-epithelialization. By isolating and culturing macrophages from wounds, Sindrilaru et al (3) observed that different phenotypes were generated in response to various microenvironmental stimuli. Macrophages continuously express M1 (classic activation) and M2 (alternative activation) surface markers throughout wound healing, with the M1 and M2 types dominating at the beginning of the inflammatory response and at the repair phase, respectively $(4,5)$. As profibrotic cells, M2 macrophages secrete cytokines, which activate the transformation of fibroblasts into myofibroblasts, thus promoting cicatrization by leading to the overgrowth of granulation tissues and deposition of extracellular matrix (ECM) (6).

Eukaryotic initiation factor 6 (eIF6), which regulates the initial translation of eukaryotes, binds to large ribosomal subunit $60 \mathrm{~S}$ in cell nuclei to inhibit the formation of $80 \mathrm{~S}$ ribosomes (7). At the beginning of protein translation, eIF6 is depolymerized from the $60 \mathrm{~S}$ subunit through phosphorylation under the action of casein kinase 1-protein kinase $\mathrm{C}$, which facilitates the binding between $40 \mathrm{~S}$ and $60 \mathrm{~S}$ subunits to form the $80 \mathrm{~S}$ subunit, thereby initiating the translation process (8). Our previous study compared the wound healing outcomes of eIF6 wild-type $\left(\mathrm{eIF}^{+/+}\right)$and knockout $\left(\mathrm{IF6}^{+/}\right)$mice, and found that the latter had significantly more granulation tissue and collagen, indicating that eIF6 inhibited skin fibrosis (unpublished data). However, the mechanism by which eIF6 affects macrophages, wound healing and cicatrization remains to be elucidated. The present study aimed to identify the target gene by comparing the gene expression profiles of M2 macrophages in $\mathrm{eIF6}^{+/+}$and $\mathrm{eIF6}^{+/-}$mice with microarrays. This may provide theoretical evidence for the role of eIF6 in inhibiting fibrosis, and a novel therapy strategy for mitigating scar repair and fibrosis in clinical practice.

\section{Materials and methods}

Experimental animals and reagents. A total of 24 male eIF6 wild-type $\left(\mathrm{eIF}^{+/+}\right)$and knockout $\left(\mathrm{eIF6}^{+/}\right) \mathrm{C} 57 \mathrm{BL} / 6$ mice (8-10 weeks old; 15-20 g; Beijing HFK Bioscience Co., Ltd., Beijing, China) were used in the present study. The mice were 
maintained in a temperature $\left(18-22^{\circ} \mathrm{C}\right)$ and humidity $(50-60 \%)$ controlled environment with ad libitum access to food and water. $\mathrm{eIF}^{+/+}$and $\mathrm{eIF}^{+/-}$mice were maintained in $12 \mathrm{~h} / 12 \mathrm{~h}$ and $22 \mathrm{~h} / 22 \mathrm{~h}$ light/dark cycles, respectively. Culture medium comprising RPMI 1640 and fetal bovine serum was purchased from Gibco; Thermo Fisher Scientific, Inc. (Waltham, MA, USA). Recombinant mouse interleukin-4 (IL-4) was purchased from Sigma-Aldrich (St. Louis, MO, USA). The following monoclonal mouse antibodies were purchased from Abcam (Cambridge, MA, USA): Anti-F4/80-peridinin chlorophyll protein complex (PerCP; 1:1,200 dilution; cat. no. ab111101), anti-CD11b-fluorescein isothiocyanate (FITC; 1:900 dilution; cat. no. ab24874), anti-Cd11c-phycoerythrin (PE; 1:1,000 dilution; cat. no. ab155349), anti-CD206(MR)-FITC (1:1,000 dilution; cat. no. ab64693) and anti-CD16/32 (1:1,200 dilution; cat. no. ab25235). The RNeasy Mini kit (cat. no. 2183018A) was provided by Life Technologies; Thermo Fisher Scientific, Inc. The AMV3.0 Reverse Transcription kit was purchased from Takara, Bio Inc. (Otsu, Japan; cat. no. RR019A). Gene microarrays (Affymetrix GeneChip Mouse Gene1.0 ST Array) were purchased from Affymetrix (Santa Clara, CA, USA). The study was approved by the ethics committee of The First Hospital of Hebei Medical University (Shizjiazhuang, China).

Culture of peritoneal macrophages. The mice were sacrificed by cervical dislocation and the peritoneal cavity of each was opened following sterilization with $75 \%$ ethanol and repeatedly lavaged with $10 \mathrm{ml}$ pre-cooled RPMI 1640 medium. The lavage fluid was collected into sterile centrifuge tubes place on ice, and centrifuged at $4^{\circ} \mathrm{C}$ and $12,000 \times \mathrm{g}$ for $5 \mathrm{~min}$ to obtain the cell precipitate, which was resuspended with $2 \mathrm{ml}$ RPMI 1640 medium, containing 10\% fetal bovine serum. Subsequently, the cells were inoculated at a density of $5 \times 10^{6}$ onto 6-well plates and cultured in an incubator for $12 \mathrm{~h}$ at $37^{\circ} \mathrm{C}$ in an incubator containing $5 \% \mathrm{CO}_{2}$, of which those exhibiting wall-adherence were identified as macrophages. The stimulated group was treated with $40 \mathrm{ng} / \mathrm{ml} \mathrm{IL-} 4$ for $24 \mathrm{~h}$ to acquire M2 macrophages, and an equal volume of phosphate-buffered saline (PBS) was added to the non-stimulated group. All other conditions were identical.

Detection of macrophage purity. The cultured macrophages were digested with $0.5 \%$ trypsin (Sigma-Aldrich), counted at the density of $5 \times 10^{5} /$ tube, washed once with PBS, resuspended in $100 \mu \mathrm{l}$ PBS and incubated with $1 \mu \mathrm{l}$ anti-CD16/32 for $10 \mathrm{~min}$ at $37^{\circ} \mathrm{C}$ to block the $\mathrm{Fc}$ receptor. The cells were then incubated with $1 \mu \mathrm{l}$ anti-F4/80-Percp and $1 \mu \mathrm{l}$ anti-CD11b-FITC at room temperature for $30 \mathrm{~min}$, washed with $1 \mathrm{ml}$ PBS to remove free antibodies, and resuspended in $0.3 \mathrm{ml}$ PBS. Finally, the expression levels of F4/80 and CD11b on the cell surface were detected using an Attune Flow Cytometer (Applied Biosystems; Thermo Fisher Scientific, Inc.).

Detection of surface markers on M2 macrophages. The stimulated macrophages were digested with $0.5 \%$ trypsin, counted at a density of $5 \times 10^{5} /$ tube, washed once with PBS, resuspended in $100 \mu \mathrm{l}$ PBS and incubated with $1 \mu \mathrm{l}$ anti-CD16/32 for $10 \mathrm{~min}$ to block the Fc receptor. Subsequently, the cells were incubated with anti-F4/80-Percp, anti-CD11c-PE and anti-CD206 (MR) -FITC (1 $\mu \mathrm{l} \mathrm{each)} \mathrm{at} \mathrm{room} \mathrm{temperature} \mathrm{for} 30 \mathrm{~min}$, washed with
$1 \mathrm{ml}$ of PBS to remove free antibodies, and resuspended in $0.3 \mathrm{ml}$ PBS. Finally, the expression levels of F4/80, CD11c and CD206 on the cell surface were detected using flow cytometry.

Gene microarray analysis. The RNAs of the M2 macrophages from the eIF6 ${ }^{+/+}$and $\mathrm{eIF}^{+/-}$mice were extracted and subjected to gene microarray analysis in triplicate. The detailed information is available at http://www.affymetrix.com.

Reverse transcription-quantitative polymerase chain reaction $(R T-q P C R)$ analysis. Total RNA (1 g) was extracted from the macrophages using an RNeasy Mini kit and transcribed into cDNA. Then, qPCR was performed in a $10 \mu \mathrm{l}$ reaction system using a 7700 Real-time Fluorescence Quantitative PCR System (Applied Biosystems, Thermo Fisher Scientific, Inc.) to detect the expression levels of transforming growth factor- $\beta 1$ (TGF- $\beta 1$ ), arginase-1, matrix metalloproteinase-2 (MMP-2), tissue inhibitor of metalloproteinase-2 (TIMP-2) and vascular endothelial growth factor (VEGF). The total reaction volume for PCR $(25 \mu 1)$ contained $12.5 \mu \mathrm{l} 2 \mathrm{X}$ Premix Ex Taq, $1 \mu 1$ upstream and downstream primers, $1 \mu \mathrm{l}$ cDNA and $9.5 \mu 1$ $\mathrm{ddH}_{2} \mathrm{O}$. The PCR thermal cycling conditions were as follows: $95^{\circ} \mathrm{C}$ for $10 \mathrm{~min}, 95^{\circ} \mathrm{C}$ for $10 \mathrm{sec}, 60^{\circ} \mathrm{C}$ for $30 \mathrm{sec}$ and $72^{\circ} \mathrm{C}$ for $20 \mathrm{sec}$, with 40 cycles in total. Primers were synthesized by Shanghai Sangon Biotech Co., Ltd. (Shanghai, China) and the sequences were as follows: GAPDH, sense 3'-GGGGAA GGTGAAGGTCGGAGTC-5' and antisense 3'-TCGCTCCTG GAAGATGGTGATG-5'; TGF- $\beta 1$, sense 3'-TGGAAACCC ACAACGAAATCTATGA-5' and antisense 3'-TGGAAACCC ACAACGAAATCTATGA-5'; arginase-1, sense 3'-CTCCAA GCCAAAGTCCTTAGAG-5' and antisense 3'-GGAGCTGTC ATTAGGGACATCA-5'; MMP-2, sense 3'-ACCTGAACA CTTTCTATGGCTG-5' and antisense 3'-CTTCCGCATGGT CTCGATG-5'; TIMP-2, sense 3'-GCAACCCCATCAAGA GGATTC-5' and anti-sense 3'-GGGGCCGTGTAGATAAAC TCG-5'; VEGF, sense 3'-GCCAGACAGGGTTGCCATAC-5' and antisense 3'-GGAGTGGGATGGATGATGTCAG-5'. GAPDH was used as the internal reference, and the results were expressed using the $2^{-\Delta \Delta \mathrm{Cq}}$ method (9). All experiments were performed in triplicate.

ELISA. The supernatant obtained from the culture medium of macrophages following stimulation with IL-4 for $24 \mathrm{~h}$ was collected, and the expression levels of VEGF (cat. no. EK0506), MMP-2 (cat. no. EK0511) and TIMP-2 (cat. no. EK0322) were detected using ELISA kits (Boster Biological Technology Co., Ltd., Wuhan, China), in strict accordance with the manufacturer's protocol. All experiments were performed in triplicate.

Statistical analysis. All data were analyzed using SPSS 13.0 software (SPSS, Inc., Chicago, IL, USA) and expressed as the mean \pm standard deviation. Inter-group comparisons were compared using a Student's $t$-test. $\mathrm{P}<0.05$ was considered to indicate a statistically significant difference.

\section{Results}

Expression levels of surface molecules and determination of the purity of M2 macrophages. Following $24 \mathrm{~h}$ of IL-4 stimulation, the macrophages underwent marked 
A

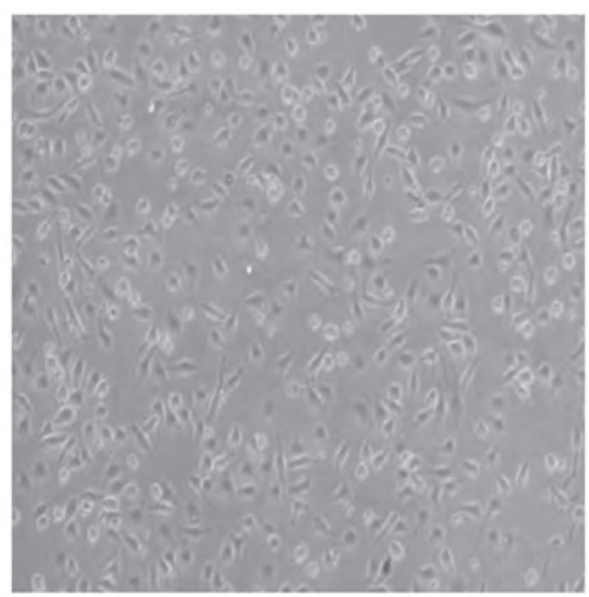

B

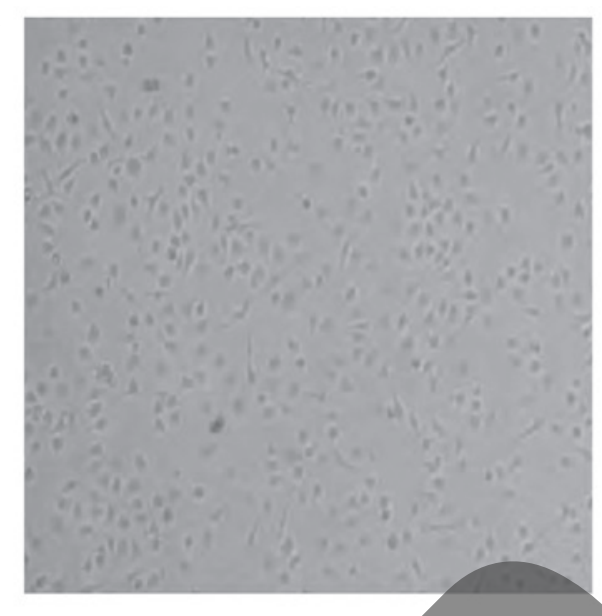

C

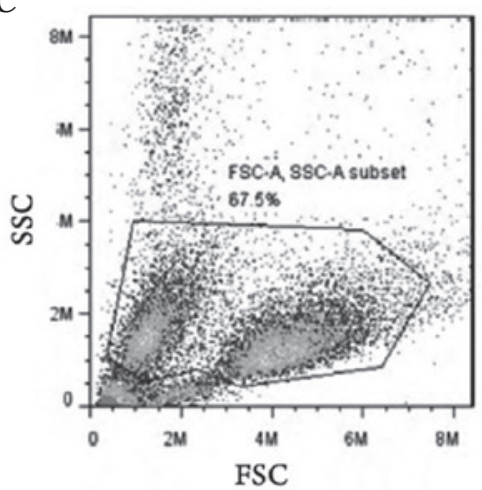

D

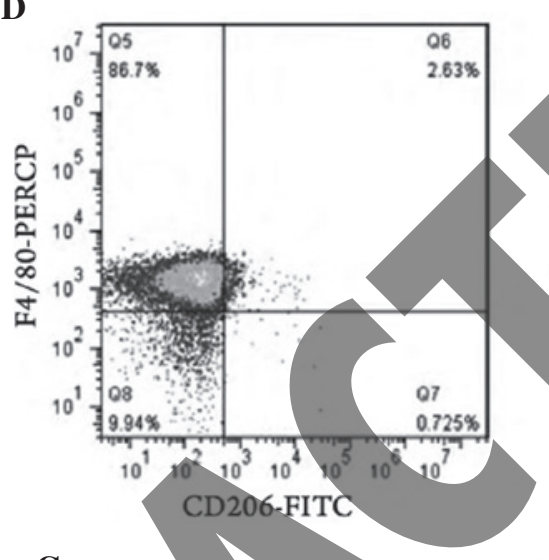

F

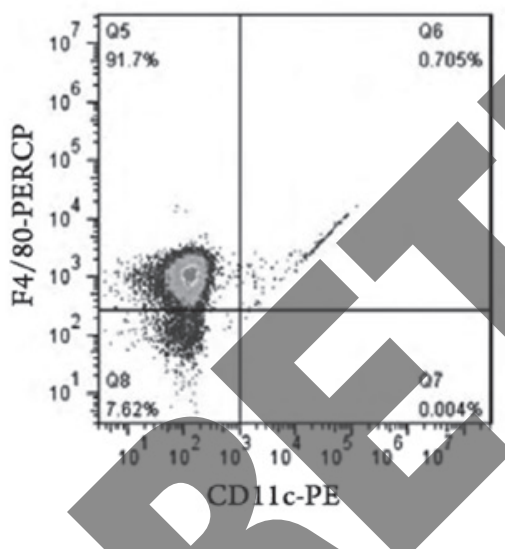

G

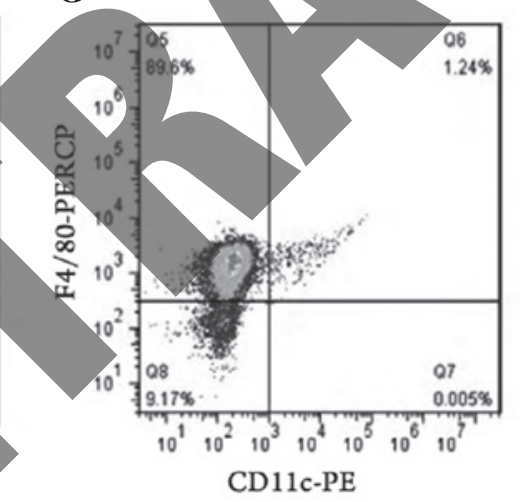

E

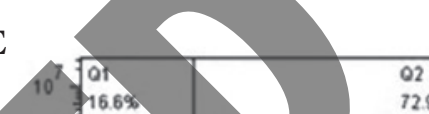

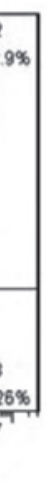

H

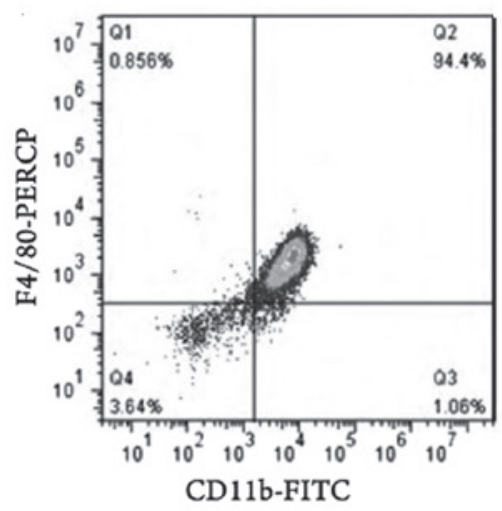

Figure 1. Purity of macrophages and expression of M2 macrophage surface markers. (A) Unstimulated macrophages (magnification, x400). (B) IL-4-stimulated macrophages (magnification, X400). (C) Subset of cultured macrophages. (D) Expression of CD206 in unstimulated macrophages. (E) Expression of CD206 in IL-4-stimulated macrophages. (F) Expression of CD11c in unstimulated macrophages. (G) Expression of CD11c in IL-4-stimulated macrophages. (H) Purity of cultured macrophages. IL-4, interleukin-4; SSC, side scatter; FSC, forward scatter; PERCP, peridinin chlorophyll protein complex; FITC, fluorescein isothiocyanate PE, phycoerythrin.

morphological changes, including decreased dendritic branches, cell rounding and reduced refractive index (Fig. 1A and B). Flow cytometry showed that the expression of CD206 in the IL-4 stimulated group was significantly increased, compared with that in the non-stimulated group (Fig. 1C-E), whereas the change in the expression of CD11c was minimal (Fig. 1F and G). The purity of the M2 macrophages was 94.4\% (Fig. 1H).

Function of 22 macrophages. Under in vitro culture conditions, the macrophages were induced into M2 macrophages in the present study through stimulation with IL-4, according to a classical method (10). As detected by RT-qPCR, the expression levels of arginase- 1 and TGF- $\beta 1$ in the $\mathrm{eIF6}^{+/+}$and $\mathrm{eIF6}^{+/-}$mice significantly increased following IL-4 stimulation $(\mathrm{P}<0.05$; Fig. 2).

Gene microarray analysis. A total of 1,716 differentially expressed genes were screened out of the gene expression profiles of the M2 macrophages from the eIF6 ${ }^{+/+}$and eIF6 ${ }^{+/-}$ mice. Compared with the $\mathrm{eIF}^{+/+}$mice, 851 genes in the macrophages of the $\mathrm{IF}^{+/-}$mice were downregulated and 


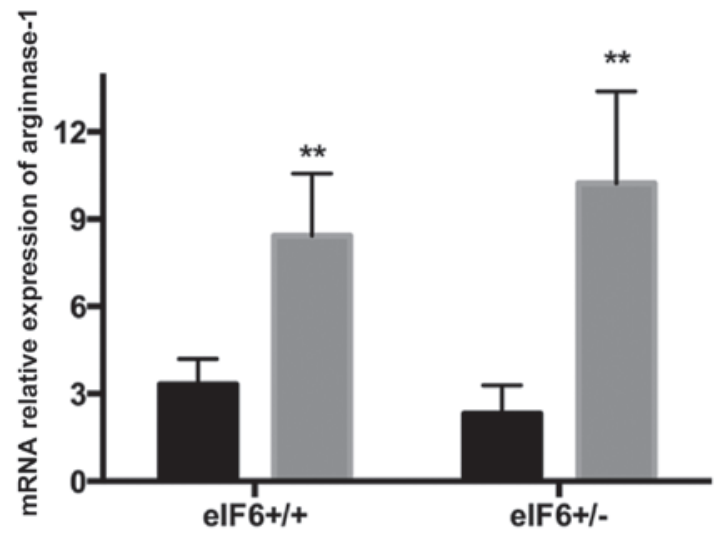

Unstimulated

IL-4 stimulated

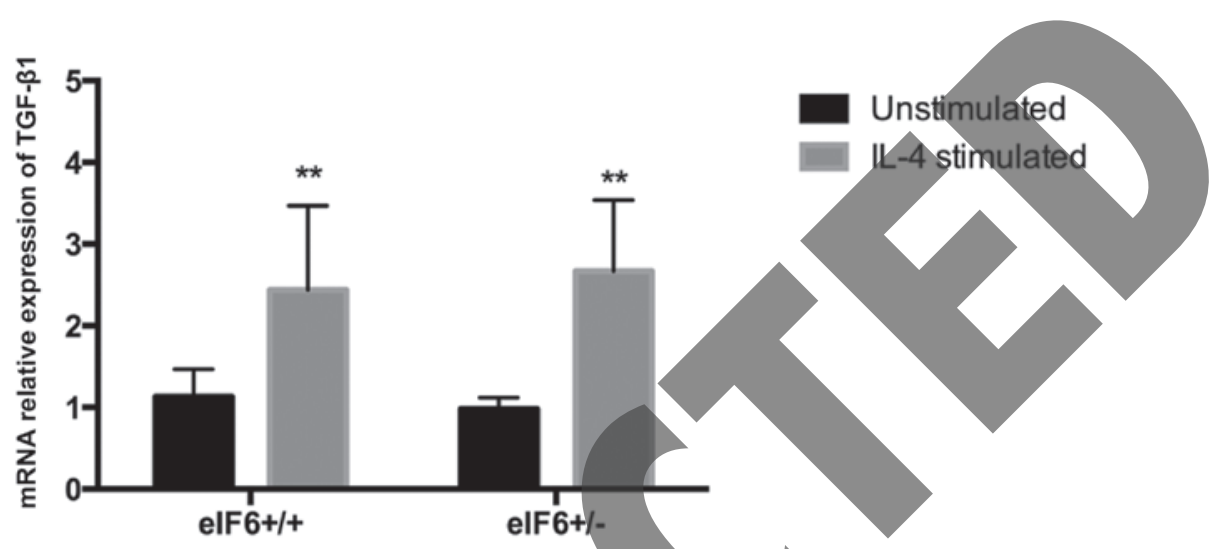

Figure 2. Expression levels of arginase-1 and TGF- $\beta 1$ in M2 macrophages. mRNA expression levels of arginase-1 and TGF- $\beta 1$ were determined using reverse transcription-quantitative polymerase chain reaction analysis. Data are presented as the mean \pm standard deviation. ${ }^{* *} \mathrm{P}<0.05$, compared with the unstimulated cells. eIF6, eukaryotic initiation factor 6; TGF- $\beta 1$, transforming growth factor- $\beta 1$; IL-4, interleukin-4.

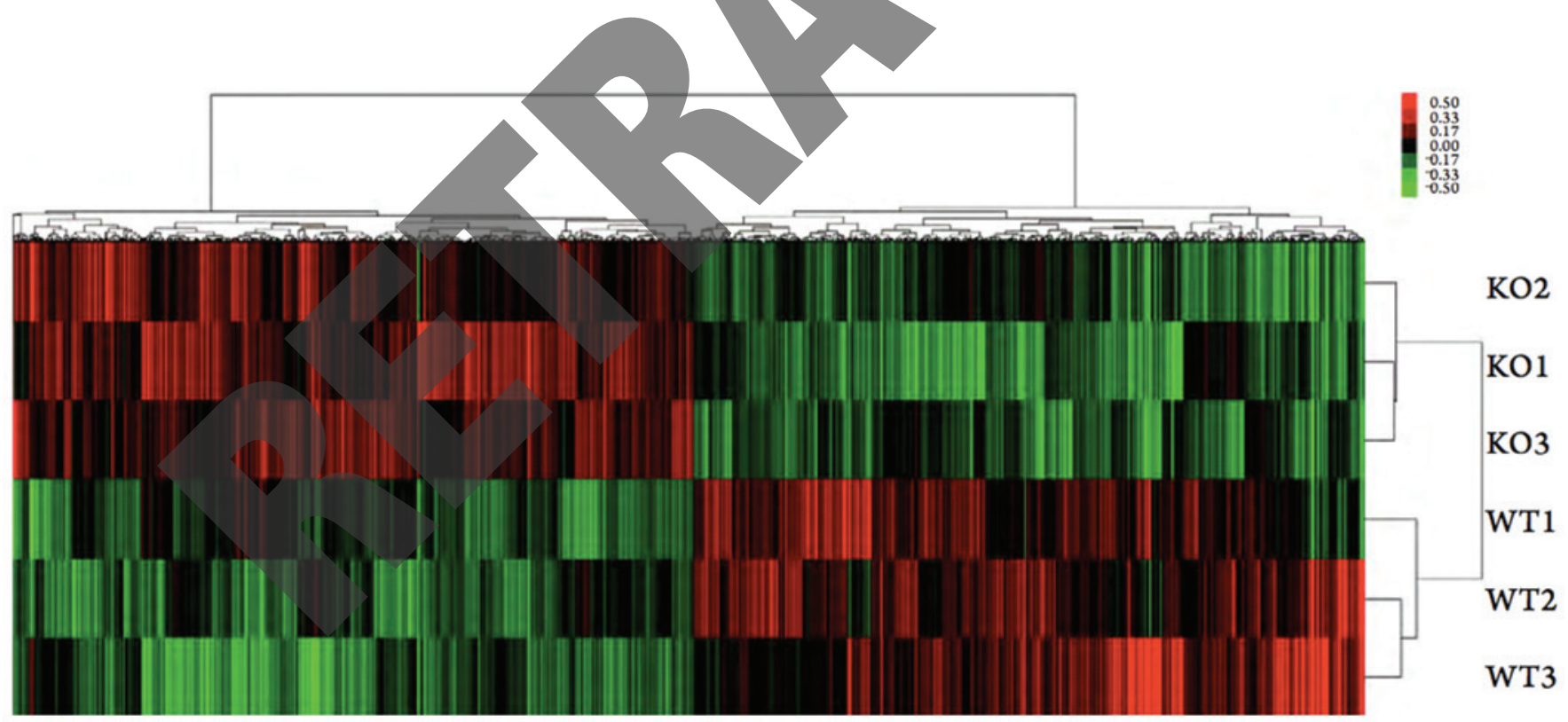

Figure 3. Gene microarray analysis. Red, low gene expression; green, high gene expression. KO, knockout; WT, wild type.

865 were upregulated (Fig. 3). The expressions levels of fibrosis-associated genes, VEGF $\left(\mathrm{eIF6}^{+/+} / \mathrm{eIF6}^{+/}=0.75 ; \mathrm{P}<0.05\right)$ and TIMP-2 $\left(\mathrm{eIF}^{+/+} / \mathrm{eIF}^{+/-}=0.65 ; \mathrm{P}<0.05\right)$ in the M2 macrophages of the $\mathrm{eIF}^{+/+}$mice were significantly downregulated, whereas the expression of MMP-2 was significantly upregulated $\left(\mathrm{eIF6}^{+/+} / \mathrm{eIF6}^{+/-}=1.3 ; \mathrm{P}<0.05\right)$. However, the expression levels of other cytokines associated with wound healing and fibrosis, including epidermal growth factor (EGF), fibroblast growth factor (FGF) and platelet-derived growth factor (PDGF), were similar (data not shown).

Validation of gene microarray results using $R T-q P C R$. Compared with the $\mathrm{IF} 6^{+/-}$mice, the M2 macrophages of the $\mathrm{eIF}^{+/+}$mice expressed significantly lower levels of VEGF and 

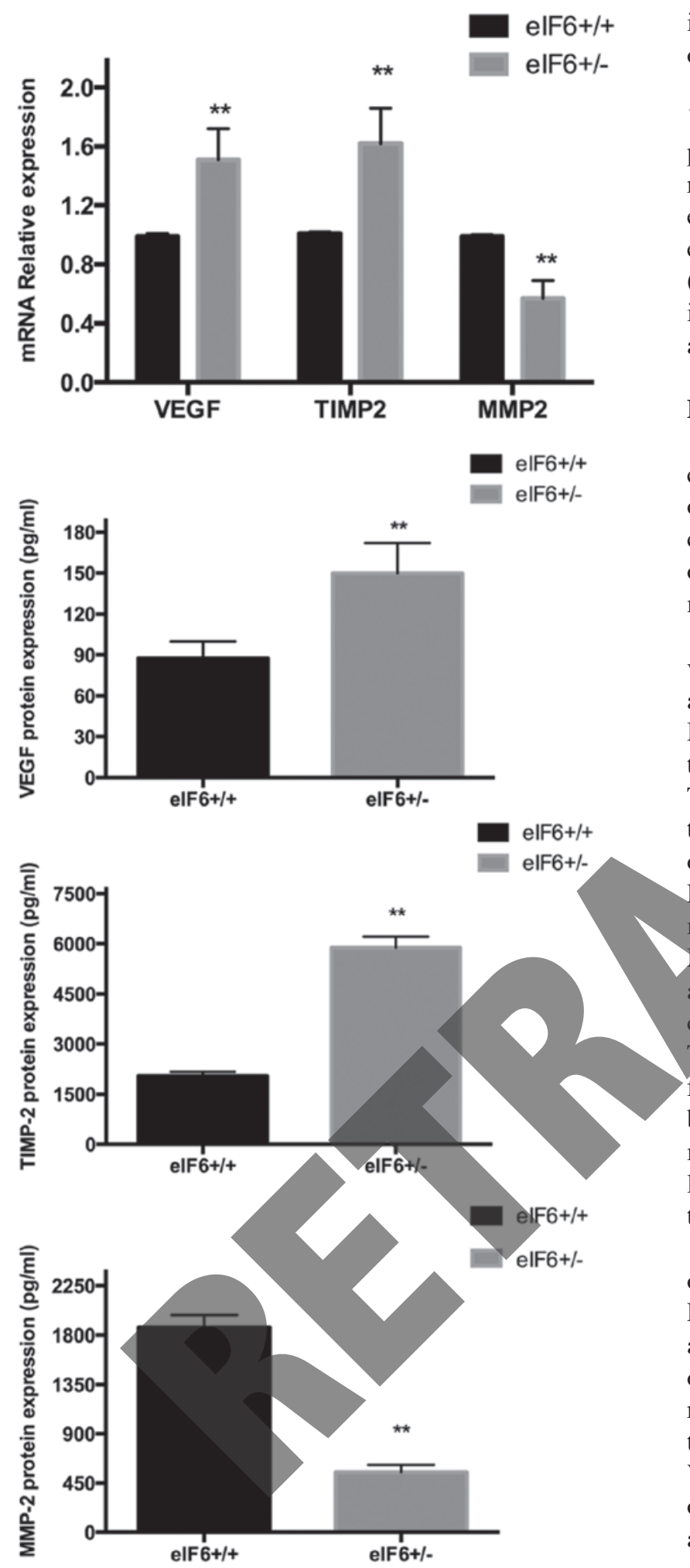

Figure 4. mRNA expression levels of TIMP-2, MMP-2 and VEGF in M2 macrophages. mRNA levels were determined by reverse transcription-quantitative polymerase chain reaction analysis, and protein expression levels were determined by ELISA. Data are presented as the mean \pm standard deviation. ${ }^{* * *} \mathrm{P}<0.05$, compared with eIF6 ${ }^{+/+} \mathrm{M} 2$ macrophages. eIF6, eukaryotic initiation factor 6; TIMP, tissue inhibitor of metalloproteinase-2; MMP-2, matrix metalloproteinase-2; VEGF, vascular endothelial growth factor.

TIMP-2 ( $<<0.05)$, and a significantly higher level of MMP-2 $(\mathrm{P}<0.05$; Fig. 4), consistent with the results of the gene microarray analysis. No significant inter-group differences were identified between the expression levels of EGF, TGF- $\beta 1$, FGF or PDGF (data not shown).

Validation using ELISA. The supernatants of the M2 macrophages from the $\mathrm{eIF}^{+/+}$and $\mathrm{eIF}^{+/-}$groups were collected, respectively, for analysis using ELISA. Compared with the $\mathrm{eIF}^{+/-}$mice, the M2 macrophages from the $\mathrm{IF}^{+/+}$mice expressed significantly lower levels of VEGF and TIMP-2 $(\mathrm{P}<0.05)$, whereas the level of MMP-2 was significantly higher in the eIF6 ${ }^{+/+}$mice $(\mathrm{P}<0.05$; Fig. 4). These results were also in accordance with the results of the gene microarray analysis.

\section{Discussion}

eIF6 is a fibrosis-inhibitory gene, however, its mechanism of action remains to be fully elucidated. Macrophages are crucial in wound healing and fibrosis, thereforem, the aim of the present study was to investigate the effects of eIF6 on macrophages.

As multifunctional adaptive cells, macrophages can activate fibroblasts by secreting large quantities of cytokines, and are involved in ECM metabolism by regulating the MMP-2/TIMP-2 balance (11). Under in vitro culture conditions, M2 macrophages can be produced by induction with T helper 2 cytokines, including IL-4 and IL-13 (3,4). Different types of macrophages are now predominantly identified based on differences between membrane protein expression levels. For example, F4 $/ 80^{+} \mathrm{CD} 11 \mathrm{c}^{-} \mathrm{CD} 206^{+}$macrophages are $\mathrm{M} 2$ macrophages $(12,13)$. With the ability to express arginase-1, M2 macrophages are involved in the metabolism of ECM and mediate its damage repair function. In addition, they can secrete anti-inflammatory factors, including IL-10 and TGF- $\beta 1$ (14). In the present study, macrophages were isolated from the peritoneal cavity and induced into M2 macrophages by being stimulated with $40 \mathrm{ng} / \mathrm{ml} \mathrm{IL-4}$ for $24 \mathrm{~h}$. Flow cytometric and RT-qPCR analyses showed that the expression levels of CD206, arginase- 1 and TGF- $\beta 1$ were identical to those in the M2 macrophages obtained from wounds (4).

Granulation tissues, which are predominantly comprised of fibroblasts, inflammatory cells, new blood vessels and ECM (15), initially fill the wound defect and promote healing, and finally transform into scar tissue. Therefore, the quantity of granulation tissue produced determines the severity of scarring (16). In particular, angiogenesis predominantly controls the formation of granulation tissues (17). Macrophages secrete VEGF (18), which facilitates the migration and proliferation of vascular endothelial cells, as well as accelerating wound angiogenesis $(19,20)$. In hypertrophic scars, numerous microvessels form, and the expression of VEGF markedly increases (21). In addition, inhibiting VEGF prevents the production of TGF- $\beta 1$ via the PI3K-Akt signaling pathway, thereby suppressing pulmonary fibrosis (22). Accordingly, VEGF dominates in cicatrization and fibrosis. The expression of VEGF was significantly lower in the M2 macrophages from the $\mathrm{eIF}^{+/+}$mice, compared with those of the $\mathrm{eIF}^{+/-}$mice, indicating that eIF6 decreased angiogenesis and affected scar tissue formation by inhibiting the production of VEGF.

Scars are also typified by considerable ECM deposition, and its metabolism is regulated by MMPs. MMPs are proteins, which are able to degrade ECM, of which MMP-2 (also known 
as gelatinase) is involved in ECM remodeling (23) by hydrolyzing type I/IV/V collagens, fibronectin and laminin $(24,25)$. As specific inhibitory factors of MMPs, TIMPs form MMP-TIMP complexes by binding to the zinc active center, thus inhibiting the binding between MMPs and substrates. Therefore, the balance between MMPs and TIMPs has a marked effect on tissue repair and the growth of new epidermal cells. In the present study, compared with the $\mathrm{IF}^{+/-}$mice, the expression of MMP-2 in the M2 macrophages of the eIF6 ${ }^{+/+}$ mice was increased, however, the expression of TIMP-2 was decreased, suggesting that eIF6 regulated the balance between MMP-2 and TIMP-2, accelerated ECM metabolism, reduced its deposition and eventually mitigated fibrosis.

In conclusion, the present study demonstrated that eIF6 relieved fibrosis/cicatrization by inhibiting the generation of VEGF to prevent the overgrow th of blood vessels and production of granulation tissues, and by regulating the MMP-2/TIMP-2 balance to promote ECM degradation and decrease its deposition. Therefore, eIF6 is a novel fibrosis-inhibitory gene, the functional analysis of which may lead to improvements in alleviating scarring.

\section{References}

1. Ploeger DT, Hosper NA, Schipper M, Koerts JA, de Rond S and Bank RA: Cell plasticity in wound healing: Paracrine factors of M1/ M2 polarized macrophages influence the phenotypical state of dermal fibroblasts. Cell Commun Signal 11: 29, 2013

2. Lucas T, Waisman A, Ranjan R, Roes J, Krieg T, Müller Roers A and Eming SA: Differential roles of macrophages diverse phases of skin repair. J Immunol 184: 3964-3977, 2010

3. Sindrilaru A, Peters T, Wieschalka S, Baican C, Baican A Peter H, Hainzl A, Schatz S, Qi Y, Schlecht A, et al: An unrestrained proinflammatory M1 macrophage population induced by iron impairs wound healing in humans and mice.J Clin Invest 121: 985-997, 2011.

4. Daley JM, Brancato SK, Thomay AA, Reichner JS and Albina JE: The phenotype of murine wound macrophages. J Leukocyte Biol 87: 59-67, 2010.

5. Ferrante CJ, Pinhal-Enfield G. Elson G, Cronstein BN, Hasko G, Outram S and Leibovich SJ: The adenosine-dependent angiogenic switch of macrophages to an M2-like phenotype is independent of interleukin-4 receptor alpha (HL-4R 2 ) signaling. Inflammation 36: 921-931, 2013.

6. Mirza R, DiPietro LA and Koh TJ: Selective and specific macrophage ablation is detrimental to wound healing in mice. Am J Pathol 175: 2454-2462, 2009.

7. Wang Z, Chen J, Sun J, Cui Z and Wu H: RNA interference-mediated silencing of eukaryotic translation initiation factor 3, subunit B (EIF3B) gene expression inhibits proliferation of colon cancer cells. World J Surg Oncol 10: 119, 2012.

8. Ceci M, Gaviraghi C, Gorrini C, Sala LA, Offenhäuser N, Marchisio PC and Biffo S: Release of eIF6 (p27BBP) from the $60 \mathrm{~S}$ subunit allows $80 \mathrm{~S}$ ribosome assembly. Nature 426 : 579-584, 2003.

9. Livak KJ and Schmittgen TD: Analysis of relative gene expression data using real-time quantitative PCR and the $2^{-\Delta \Delta C}$ method. Methods 25: 402-408, 2001.
10. Raes G, De Baetselier P, Noël W, Beschin A, Brombacher F and Hassanzadeh Gh G: Differential expression of FIZZ1 and Ym1 in alternatively versus classically activated macrophages. J Leukoc Biol 71: 597-602, 2002.

11. Nishimura S, Manabe I, Nagasaki M, Eto K, Yamashita H, Ohsugi M, Otsu M, Hara K, Ueki K, Sugiura S, et al: CD8+ effector T cells contribute to macrophage recruitment and adipose tissue inflammation in obesity. Nat Med 15: 914-920, 2009.

12. Lee S, Huen S, Nishio H, Nishio S, Lee HK, Choi BS, Ruhrberg C and Cantley LG: Distinct macrophage phenotypes contribute to kidney injury and repair. J Am Soc Nephrol 22: 317-326, 2011.

13. Li W, Zhang Q, Wang M, Wu H, Mao F, Zhang B, Ji R, Gao S, Sun Z, Zhu W, et al: Macrophages are involved in the protective role of human umbilical cord-derived stromal cells in renal ischemia-reperfusion injury. Stem Cell Res 10: 405-416, 2013.

14. Wynn TA and Barron L: Macrophages: Master regulators of inflammation and fibrosis. Semin Liver Dis 30: 245-257, 2010.

15. Nayak BS, Kanhai J, Milne DM, Swanston WH, Mayers S, Eversley M and Rao AV: Investigation of the wound healing activity of Carapa guianensis L. (Meliaceae) bark extract in rats using excision, incision and dead space wound models. J Med Food 13: 1141-1146, 2010.

16. Hess CL, Howard MA and Attinger CE: A review of mechanical adjuncts in wound healing: Hydrotherapy, ultrasound, negative pressure therapy, hyperbaric oxygen and electrostimulation. Ann Plas Surg 5 :

17. Rajkumar VS, Shiwen X, Bostrom M, Leoni P, Muddle J, Ivarsson M, Gerdin B, Denton CP, Bou-Gharios G, Black CM and Abraham DJ: Platelet-deriyed growth factor-beta receptor activation is essential for fibroblast and pericyte recruitment during cutaneous wound healing. Am J Pathol 169: 2254-2265, 2006.

8. Goto F, Goto K, Weindel K and Folkman J: Synergistic effects of vascular endothelial growth factor and basic fibroblast growth factor on the proliferation and cord formation of bovine capillary endothelial cells within collagen gels. Lab Invest 69: 508-517, 1993

Mori R, Tanaka K, de Kerckhove M, Okamoto M, Kashiyama K, Tanaka K, Kim S, Kawata T, Komatsu T, Park S, et al: Reduced FOXO1 expression accelerates skin wound healing and attenuates scarring. Am J Pathol 184: 2465-2479, 2014.

Senger DR, Ledbetter SR, Claffey KP, Papadopoulos-Sergiou A Peruzzi CA and Detmar M: Stimulation of endothelial cell migration by vascular permeability factor/vascular endothelial growth factor through cooperative mechanisms involving the alphavbeta3 integrin, osteopontin and thrombin. Am J Pathol 149: 293-305, 1996.

21. van der Veer WM, Bloemen MC, Ulrich MM, Molema G, van Zuijlen PP, Middelkoop E and Niessen FB: Potential cellular and molecular causes of hypertrophic scar formation. Burns 35: 15-29, 2009.

22. John GB, Cheng CY and Kuro-o M: Role of Klotho in aging, phosphate metabolism and CKD. Am J Kidney Dis 58: 127-134, 2011.

23. Swiderski RE, Dencoff JE, Floerchinger CS, Shapiro SD and Hunninghake GW: Differential expression of extracellular matrix remodeling genes in a murine model of bleomycin-induced pulmonary fibrosis. Am J Pathol 152: 821-828, 1998.

24. Hamacher S, Matern S and Roeb E: Extracellular matrix-from basic research to clinical significance. An overview with special consideration of matrix metalloproteinases. Dtsch Med Wochenschr 129: 1976-1980, 2004 (In German).

25. McCawley LJ and Matrisian LM: Matrix metalloproteinases: They're not just for matrix anymore! Curr Opin Cell Biol 13: 534-540, 2001. 